\title{
An Overlap Syndrome involving systemic lupus erythematosus and autoimmune hepatitis in an adolescent girl
}

\author{
Cristina BattagliottiM.D. ${ }^{a}$, DanielaRispolo KlubekM.D. ${ }^{a}$, Mario KarakachoffM.D. ${ }^{a}$ and Alejandro Costaguta M.D. ${ }^{a}$
}

\begin{abstract}
Overlap of systemic lupus erythematosus and autoimmune hepatitis is a rare condition, occasionally described.

Both autoimmune diseases can share common autoimmune features such as polyartralgia, hypergammaglobulinemia and positive antinuclear antibody, but they have been considered as two different entities.

We report a 14 year old female patient with systemic lupus erythematosus who developed autoimmune hepatitis two years later.

She had jaundice with no history of viral infections, drug intake, alcohol abuses or exposition to blood products. She was positive for antinuclear antibody, double stranded DNA antibody and LKM 1 antibody.

Histological examination of the liver showed interface hepatitis with lymphoplasmacytic cell infiltration.

The patient satisfied the international criteria for both systemic lupus erythematosus and Type 2 autoimmune hepatitis. Clinical symptoms and laboratory findings improved under treatment with steroids and mycophenolate mofetil.

Conclusion. Autoimmune hepatitis may occur during the course of systemic lupus erythematosus and an early diagnosis is important for preventing advanced liver disease.

Definitive diagnosis of autoimmune hepatitis requires confirmation by means of a liver biopsy.

Key words: autoimmune hepatitis, connective tissue diseases, systemic lupus erythematosus.
\end{abstract}

http:/ /dx.doi.org/10.5546/aap.2016.eng.e155

\section{INTRODUCTION}

Systemic Lupus Erythematosus (SLE) is a systemic, autoimmue cronic disease, that can affect multiple organs including the liver. ${ }^{1,2}$ The frequency of liver compromise is low and ranges from 8 to $23 \%$ in different series.-5

a. Dr. Orlando Alassia Childrens' Hospital. Santa Fe. Argentina.

E-mail address:

Cristina Battagliotti M.D: cristinabattagliotti@yahoo.com.ar

Funding: None.

Conflict of interest: None.

Received: 8-21-2015

Accepted: 12-16-2015
Autoimmune hepatitis (AIH) is a chronic progressive disease of unknown cause, characterized by elevated levels of hepatic enzymes, hypergammaglobulinemia with presence of auto antibodies, and characteristic histological findings. ${ }^{6}$

The two diseases differ mainly in their physiopathology. SLE is a disease caused by autoimmune complexes, in which nuclear antigens, antinuclear antibodies and the complement system are involved (non-organ specific), whereas autoimmune hepatitis is characterized by prominent inflammatory infiltrate of lymphoplasmacytic type, (cell mediated damage) directed to a liver autoantigen (organ specific). ${ }^{2}$

Although rare, cases of SLE and AIH simultaneous occurrence has been occasionally reported, and well documented. 7,8

We present a 14 year-old SLE patient who developed Type 2 AIH two years later.

We emphasize the diagnosis difficulties presented in the coexistence of these two entities.

\section{CLINICAL CASE}

A 16 year-old Caucasian female patient was diagnosed SLE with nephropathy class IV. (Diffuse Proliferative)

She had weight loss, fatigue, anemia, alopecia, butterfly rash, bilateral symetric articular compromise, and pitting edema.

The patient showed 6 of 11 American College of Rheumatology (ACR) criteria for SLE.

She was initially treated with intravenous cyclophosphamide and corticosteroids for the first six months, followed by mycophenolatemofetil $1 \mathrm{~g} / \mathrm{d}$ and hydroxychloroquine to maintain remission during tapering of steroids. Elevated liver enzymes (AST 97 UI/L -ALT 301 UI/L) with no associated clinical signs were observed four months later, and subsequently normalized. During the following months the patient remained in stable clinical condition with normalization of biochemical tests.

After two years, she developed jaundice with elevated liver enzymes (AST $1480 \mathrm{UI} / \mathrm{L}$; ALT 1320 UI/L; Gamma GT 214 UI/L; total Bilirubin 
$6,29 \mathrm{mg} / \mathrm{dl}$ (direct $5.47 \mathrm{mgmg} / \mathrm{dl}$ ), with positive result for double stranded DNA antibodies, low C4 levels and presence of anti LKM antibody. (Table 1) She denied alcohol or drug intake, or of previous blood transfusions. Serologic tests for hepatotropic virus including CMV and EBV resulted negative.

Liver biopsy showed chronic hepatitis with periportal inflammatory infiltrate of lymphoplasmacytic type with interface hepatitis, but no fibrosis (Figure 1).

Since the patient met type $2 \mathrm{AIH}$ diagnosis criteria, prednisone dose was increased to $60 \mathrm{mg} /$ day for four weeks, and tapered according to the result of liver tests. Mycophenolate mofetil was continued.

The patient showed satisfactory clinical remission and normalization of biochemical tests over the following weeks, remaining stable during the last two years of follow-up.

\section{DISCUSSION}

Overlapping AIH and SLE, as these two entites can occur together, is a rare observation. ${ }^{2-8}$

TABLE 1: Laboratory findings at diagnosis of SLE and AIH

\begin{tabular}{lcc}
\hline & SLE diagnosis & AIH diagnosis \\
\hline AST (0-32UI/L) & $40 \mathrm{UI} / \mathrm{L}$ & $1,480 \mathrm{UI} / \mathrm{L}$ \\
ALT(0-31UI/L) & $29 \mathrm{UI} / \mathrm{L}$ & $1,320 \mathrm{UI} / \mathrm{L}$ \\
Total bilirrubin (0-1.10 mg\%) & $0.56 \mathrm{mg} / \mathrm{dl}$ & $6,29 \mathrm{mg} / \mathrm{dl}$ \\
Direct bilirrubin (0-0.3mg\%) & $0.26 \mathrm{mg} / \mathrm{dl}$ & $5.47 \mathrm{mg} / \mathrm{dl}$ \\
Gamma GT & $72 \mathrm{UI} / \mathrm{L}$ & $214 \mathrm{UI} / \mathrm{L}$ \\
IgG & $1.368 \mathrm{mg} / \mathrm{dl}$ & $1.500 \mathrm{mg} / \mathrm{dl}$ \\
C3 & $14 \mathrm{mg} / \mathrm{dl}$ & $97 \mathrm{mg} / \mathrm{dl}$ \\
C4 & $2 \mathrm{mg} / \mathrm{dl}$ & $6 \mathrm{mg} / \mathrm{dl}$ \\
ANA & $+1 / 5.120$ & $+1 / 100$ \\
Anti DNA & $+1 / 640$ & $+1 / 564$ \\
ANA screening & + & + \\
Anti Ro/SSA & - & + \\
Anti La/SSB & + & - \\
Anti Sm & - & - \\
Anti RNP & - & - \\
ASMA & & - \\
SLA & & - \\
LKM1 & & - \\
LC1 & & - \\
\hline
\end{tabular}

ANA: antinuclear antibody. ANAS antinuclear screening. Anti Ro/SSA protin nuclear. Anti La /SSB anti protein nuclear. Anti Sm anti protein nuclear Smith.

Anti RN:anti ribonucleoprotein.

ASMA: antismooth muscle antibody.

SLA: antisoluble liver proteins antibody.

LKM1 anti-liver-kidney microsoma antibody.

LC1anti-:liver-cytosol antibody.
High transaminase levels are a frequent finding in SLE, affecting 23 to $55 \%$ of the patients. ${ }^{4-6}$

This is typically mild and probably multifactorial, related to drug toxicity, metabolic disorders, intercurrent viral illnesses, disease activity of LES itself, or hepatic steatosis resulting from corticosteroid treatment, among others. ${ }^{5,6}$

Vascular thrombosis, particularly BuddChiari's syndrome, should also be considered owing to the risk of thrombophilia associated with the presence of antiphospholipid antibodies observed in these patients. ${ }^{4,9}$

Despite the high incidence of enzymatic abnormalities, development of a true AIH is a rare event. ${ }^{2}$ Hepatomegaly might occur in 30 to $50 \%$ of patients with SLE, while jaundice is rarely observed, occasionally associated to hemolysis or overlapping infections. ${ }^{2,4}$

Patients diagnosed with SLE at a young age have been related to severe damage to specific organs, like kidneys or brain, which results in a more aggressive clinical course compared to adults, although chronic liver disease is a rare condition. ${ }^{7}$

Despite the fact that real immune-mediated histological hepatic injury is relatively rare in SLE, there are well documented cases in literature. Runyon et al., ${ }^{4}$ reported 4 out of 238 (1,7\%) patients with SLE having "active" chronic hepatitis or hepatic cirrhosis. Series of autopsies ${ }^{10,12}$ of patients with SLE show injuries ranging from steatosis to periportal hepatitis, even to cirrhosis in $2 \%$ of the cases.

FIGURE 1: Expanded portal space with lymphoplasmacytic infiltrate and spill-over into the lobule "interface hepatitis". HEE $40 x$

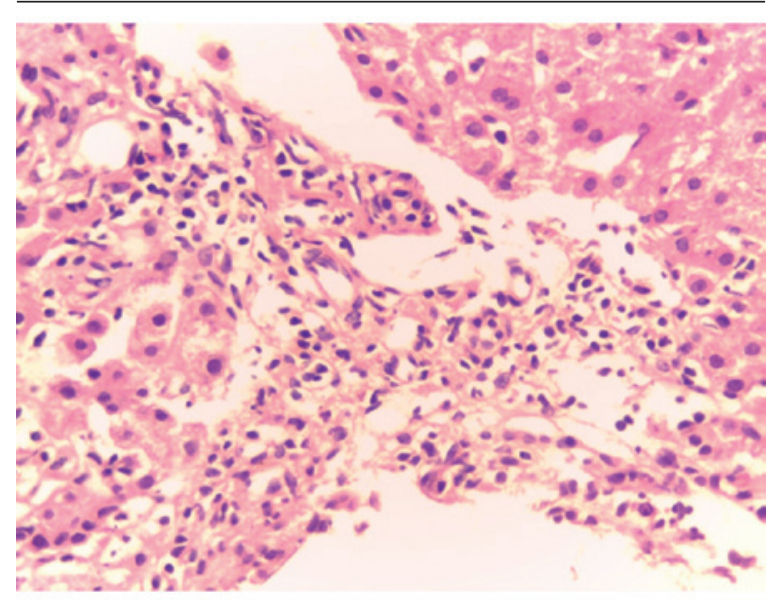


Liver damage caused by AIH, originally called "lupoid hepatitis", should be distinguished from the hepatitis associated to SLE or "lupus hepatitis", since they are probably two different entities although they can both present with polyartralgia, hypergammaglobulinemia and positive result for anti-nuclear antibodies (ANA). ${ }^{7}$ Nevertheless, patients exist with an overlapping picture of true SLE and AIH, fulfilling standard diagnostic scores for both entities. This type of patients is a minority, and diagnostic and therapeutic approach should probably be individualized by case.

Autoimmune hepatitis type 1 might have ANA and anti-smooth muscle (ASMA) with antiactin specificity, and might present extrahepatic manifestations including arthralgia, malar erythema, Coombs-positive hemolytic anemia and autoimmune thrombocytopenia. ${ }^{8}$

AIH type 2 is related to the presence of anti liverkidney microsomal type 1 (LKM) auto antibodies or anti liver-cytosol antibody (LC1) and it may also have autoimmune systemic manifestations. ${ }^{8,9,11}$

Among the serological findings for active SLE the positive result of anti-DNA antibodies is sensitive and specific. Anti ribosomal P antibodies have been recently described in patients with severe lupus. ${ }^{10}$

Findings on a liver biopsy are importance to diagnose the type of liver damage in patients with LES-HAI overlapping features in order to adjust the treatment and determine prognosis. ${ }^{3} \mathrm{~A}$ lymphoplasmacytic infiltrate of the portal spaces which extends over the limiting plate and invades the lobule ("bridging necrosis") represents the hallmark of AIH. This is in stiking contrast with the mild mononuclear infiltrate confined to portal spaces observed in some patients with SLE. These last patients show benign evolution, and do not progress to cirrhosis, being the hepatic injury an epiphenomenon of a more generalized autoimmune reaction.

Our patient presented with a histological picture characterized by interface hepatitis and chronic lymphoplasmacytic infiltrates as described in AIH. In absence of virus or other noxa, the diagnosis of AIH concomitant with SLE was suggested.

Overlapping AIH and SLE has occasionally been described in literature. Oka $\mathrm{H}^{12}$ has reported this in 5 out of 162 patients that met ACR criteria for SLE, while Tamai et al. ${ }^{13}$ reported 2 out of 21 patients with this association.

Irving et al., ${ }^{14}$ studied the prevalence of $\mathrm{AIH}$ in adults and children with SLE in a UK population, finding greater prevalence of AIH disease among SLE patients with childhood onset, even before lupus development.

Regarding treatment, the number of cases filed by Beisel $\mathrm{C}$ et al., ${ }^{15}$ SLE patients and HAI superimposed, five of them had a good response to immunosuppressive therapy presented remission. Only one patient whose first biopsy showed cirrhosis developed hepatocellular carcinoma six years after diagnosis of AIH.

Our patient responded adequately to the increase in immunosuppression with rapid improvement of clinical and biochemical parameters, remaining in remission during the last two years.

\section{CONCLUSION}

Children with liver-dysfunction and SLE should be investigated for AIH as these two entites can occur together. All SLE patients presenting with chronic rising of liver enzymes and positivity of serum auto-antibodies (ANA, SMA, LKM) should be suspected of having SLEHAI overlapping, and liver biopsy should become mandatory in such patients.

Early diagnosis is important for adjust treatment and avoid progression of hepatic disease.

\section{Acknowledgments}

To Dr. María Belén Pancera and Dr. María Fernanda Risso from the Department of Pathology at Dr. Orlando Alassia Childrens' Hospital for contributing to selection and description of the liver biopsy.

\section{REFERENCES}

1. Wallace DJ. Gastrointestinal and hepatic manifestations. En Wallace DJ, Hahn BH, eds. Dubois' Lupus Erythematosus. $5^{\text {th }}$ ed. Baltimore: Williams \& Wikins; 1997.p.835-55.

2. Bessone F, Kuzmicz G. Manifestaciones gastrointestinales en el Lupus Eritematoso Sistémico. En Battagliotti CA, Gentiletti AA, Pons Estel BA, eds. Lupus eritematoso sistémico: aspectos clínicos y terapéuticos. Buenos Aires: VDB; 2013.p.282-97.

3. Bessone F, Poles N, Roma MG. Challenge of liver disease in systemic lupus erythematosus: Clues for diagnosis and hints for pathogenesis. World J Hepatol 2014;6(6):394-409.

4. Runyon BA, LaBrecque DR, Anuras S. The spectrum of liver disease in systemic lupus erythematosus. Report of 33 histologically-proved cases and review of the literature. Am J Med 1980;69(2):187-94.

5. MokCC. Investigations and management of gastrointestinal and hepatic manifestations of systemiclupuserythematosus. Best Pract Res Clin Rheumatol 2005;19(5):741-66.

6. Abraham S, Begum S, Isenberg D. Hepatic manifestations of autoimmune rheumatic diseases. Ann Rheum Dis 
2004;63(2):123-9.

7. Battagliotti C, Russo R. Lupus Pediátrico. En Battagliotti CA, Gentiletti AA, Pons Estel BA, eds. Lupus eritematoso sistémico: aspectos clínicos y terapéuticos. Buenos Aires: VDB; 2013.p.384-93.

8. Cuarterolo M, Ciocca M, Álvarez F. Hepatitis autoinmune en niños. Perspectivas actuales. Arch Argent Pediatr 2014;112(2):169-75.

9. Avcin T, Silverman ED. Antiphospholipid antibodies in pediatric systemic lupus erythematosus and the antiphospholipid syndrome. Lupus 2007;16(8):627-33.

10. ArnettFC, Reichlin M.Lupushepatitis:an under-recognized disease feature associated with autoantibodies to ribosomal P. Am J Med 1995;99(5):465-72.

11. Deen ME,Porta G, FiorotFJ,Campos LM, etal. Autoimmune hepatitis and juvenile systemic lupus erythematosus. Lupus
2009;18(8):747-51.

12. Oka H. The survey of autoimmune hepatitis in Japan. En Annual Report of Study Group on Severe Hepatitis. Tokio: Japanese Ministry of Health and Welfare;1988:235-41.

13. Tamai Y, Kin S, Ito K, Fukase M. Application of the Preliminary SLE Classification Criteria by American Rhuematism Association to autoimmune hepatitis. Ryumachi 1974;14(2):88-94.

14. Irving KS, Sen D, Tahir H,PilkingtonC, etal. A comparison of autoimmune liver disease injuvenile and adult populations with systemic lupus erythematosus-a retrospective review of cases. Rheumatology (Oxford) 2007;46(7):1171-3.

15. Beisel C, Weiler-Normann C, Teufel A, Lohse AW. Association of autoimmune hepatitis and systemic lupus erythematodes: a case series and review of the literature. World J Gastroenterol 2014;20(35):12662-7. 